\title{
THE SECRETION OF URINE BY DEHYDRATED AND NORMAL INFANTS
}

BY

\author{
W. F. YOUNG, M.B., D.C.H., ANd R. A. MCCANCE, M.D., F.R.C.P. \\ WITH SOME TECHNICAL ASSISTANCE FROM E. FINCH, M.Sc.
}

(From the Children`s Hospital, Birmingham, and the Department of Medicine, Cambridge)

The subject of gastroenteritis and its attendant dehydration and salt deficiency has absorbed the interest and attention of all those who have been responsible for the care of infants. The serum chemistry of babies with diarrhoea and vomiting has been carefully investigated, and a few authors have examined the urine and carried out renal function tests.

High blood ureas have been found in untreated cases (Schloss, 1918; Bessau, Rosenbaum and Leichtentritt, 1922; Cohen, Miller and Kramer, 1933), and Schloss considered that haemoconcentration was not enough to account for this finding. By means of the phenolsulphonphthalein test and Ambard's coefficient of urea excretion he showed that the function of the kidney was impaired in a group of infants recovering from gastroenteritis. Schoenthal, Lurie and Kelly (1933) came to the same conclusion after examining the urea clearances of a few babies who were dehydrated. The controls in both these investigations were normal infants whose urine volumes were usually much higher than those of the sick infants.

A number of observations on the changes in the serum electrolytes have been recorded. It has been found that the bicarbonate may be diminished or increased and that the chlorides may be low or extremely high (Aldridge, (1941a). Both chlorides and bicarbonate may be high in the same patient, which suggests that the excretion of sodium may have failed.

Darrow and Buckman (1928) found that an increase in the concentration of organic crystalloids of the plasma might be associated with a diminished plasma volume, and suggested that the excretion of minerals might be deficient when the urine was scanty. Hamilton, Kajdi and Meeker (1929) recorded instances of a type of acidosis in which the total base in the plasma was high and the percentage bound as chloride was raised. They considered that functional renal deficiency and haemoconcentration might explain these changes.

Cooper (1937) found that chlorides were increased in the tissues of infants who had died after saline had been administered, and considered that this was due to renal insufficiency. Hartmann (1928) noted that chlorides were raised, and bicarbonate correspondingly reduced, in the plasma of infants whose losses by diarrhoea and vomiting were such that the volume of saline 
administered did not relieve their oliguria. Hoag and Marples (1931), however, considered that, except in moribund infants, the oliguria could always be overcome if enough fluid, including large volumes of parenteral saline, was given, and with this Cohen et al. (1933) agreed. The latter found in addition that this treatment restored the blood urea to normal. Nevertheless, these authors admitted that there was a risk of oedema in such treatment, and that the readjustment of the normal inorganic equilibrium of the blood might take some days. Day-to-day observations by Aldridge (1941b) have shown that the chlorides in the plasma may reach very high levels following the administration of saline in conventional amounts. Maizels and McArthur (1928-29) made a study, not only of the constituents of the blood, but also of the urine. Their observations were in some respects incomplete, but they recorded findings which seemed to implicate the kidney. They showed, for example, that raised plasma chlorides did not necessarily lead to a high concentration of chlorides in the urine, even if this fluid contained a high percentage of urea. Unfortunately, they did not measure the blood ureas of these cases or the minute volumes of the urine. These authors also noted that some of their patients were passing an acid urine when the $\mathrm{pH}$ of the plasma was high. Hartmann and Smyth (1926) had previously shown that the kidney might produce an acid urine from a plasma in which the bicarbonate was raised if the total base, i.e. the osmotic pressure of the plasma, was at the same time reduced. Maizels and McArthur (1929-30), however, found that the concentration of bicarbonate and chloride in the plasma were sometimes both raised and that therefore the osmotic pressure of the plasma must then have been above the normal level. They considered that an altered renal threshold for base consequent upon renal damage accounted for these observations.

It has never been suggested that infants with diarrhoea and vomiting suffer from 'nephritis.' It seemed possible, however, that they might have some functional disorganization of the kidney analogous to that studied by Borst (1938) and Black and Leese (1940) in haematemesis, McCance and Widdowson (1937a, 1937b and 1939) in alkalosis, experimental salt deficiency and diabetic coma, and by Allott (1939) in lesions of the central nervous system. It seemed desirable, therefore, to make a study of the kidney function of infants with diarrhoea and vomiting, and for this purpose to adopt the methods introduced by Möller, McIntosh and Van Slyke (1929) and Smith (1937), and used by McCance and Widdowson $(1937,1939)$ in their studies of functional renal disorganization. Since McCance and Young (1941) had recently shown that the kidneys of newborn infants functioned differently from those of adults, it was necessary to choose normal infants of the same ages as controls.

\section{Present investigation}

Subjects and methods. The subjects of the investigation included fortyone infants admitted to the gastroenteritis ward of the Children's Hospital, Birmingham, and twenty normal male babies who were convalescent. Strictly speaking, no hospital inmates can be regarded as normal, but when these babies were tested they were apyrexial and gaining weight, although some were still below the standard weight for their age. A few had been suffering from gastroenteritis and had, therefore, been examined previously.

The kidney function of infants with gastroenteritis and that of their normal 
fellows has been compared. Since a previous investigation (McCance and Young, 1941) had shown that the clearances of urea and electrolytes per metre of surface area were low at birth, and increased to the adult levels during the first year of life, the patients and the controls have been divided into two age groups: (1) those aged five to twelve weeks; (2) those aged three to eight months. Surface area has been used as the basis when the function of one age group was being compared with that of the other or with that of adults.

The male infants were nursed in cots with the head end raised about six inches. The buttocks were placed on a rubber ring and the trunk supported on pillows. Restrainers were put on the more active subjects. The urine was collected in pyrex boiling tubes, which with a little practice could be so adjusted with strips of elastic strapping that the child was not inconvenienced and no urine was lost. The infants were allowed to void urine spontaneously, and each specimen was accurately timed and removed as soon as it was passed. The first was discarded, and subsequently each was analysed separately.

Blood was obtained from the heel or through the fontanelle; the latter was used only if inulin had been given. Inulin was administered if intravenous therapy was being undertaken, and in these circumstances 4 to $8 \mathrm{gm}$. were given by vein before the kidney function tests were to be made. Samples of blood were withdrawn at suitable intervals as the concentration of inulin in the plasma fell. A curve for the plasma inulin was then drawn covering the experimental periods, and inulin clearances were thus calculated for two or three specimens of urine. In calculating clearances, plasma values at the mid-point of each period were read off the curve. The urines for these tests were diluted while still warm to maintain the inulin in solution.

When inulin clearances were not being carried out, blood for the tests was taken so far as possible midway through periods of urine collection. In all samples of blood, except those used for urea alone, the corpuscles were separated as soon as possible and discarded. Serum was used for the estimation of potassium, but heparinized plasma for all the other analyses. When chlorides or bicarbonates were to be determined, the blood was taken and the plasma separated from the corpuscles under paraffin.

The chemical estimations were made in the way described by McCance and Young (1941) and Young, Hallum and McCance (1941).

The blood pressure was taken at intervals during the observations on dehydrated babies, and several times during each inulin experiment. It was intended to use the range of sphygmomanometer cuffs recommended by Robinow, Hamilton, Woodbury and Volpitto (1939), but at first these were not all available. The same sized cuff, however, was always used for the same child and it is believed that the blood pressures were within normal limits. Only one child's blood pressure rose appreciably with the relief of dehydration, and no significant changes of blood pressure took place during any of the inulin experiments, or when urea and other clearances were being determined. It is usual for children with diarrhoea and vomiting to collapse and become almost pulseless with low blood pressures as death approaches. They may collapse in this way for short periods and recover their previous blood pressures. Both these forms of collapse have been observed and recorded, but they have not happened at times which interfered with the studies of kidney function.

Results. SERUM CHEMISTRY. Reference has already been made to some of the changes in the serum chemistry of infants with gastroenteritis. All the abnormalities recorded by previous workers have been observed, and the circumstances under which they have been noted will be discussed when the results of the kidney function tests are being described. 
Urine volume. Brock, Thomas and Peiper (1934), Cohen et al. (1933) and Aldridge (1941b) showed that oliguria was associated with the dehydration which follows diarrhoea and vomiting in infants by measuring the twenty-four hourly urine output of their patients. The present observations on the minute volumes of the urine have confirmed their findings. The inset diagrams in fig. 1 show a comparison between the frequency distribution of the minute volumes of infants aged three to eight months with and without gastroenteritis. It will be noted that thirty-one specimens of urine from infants with diarrhoea

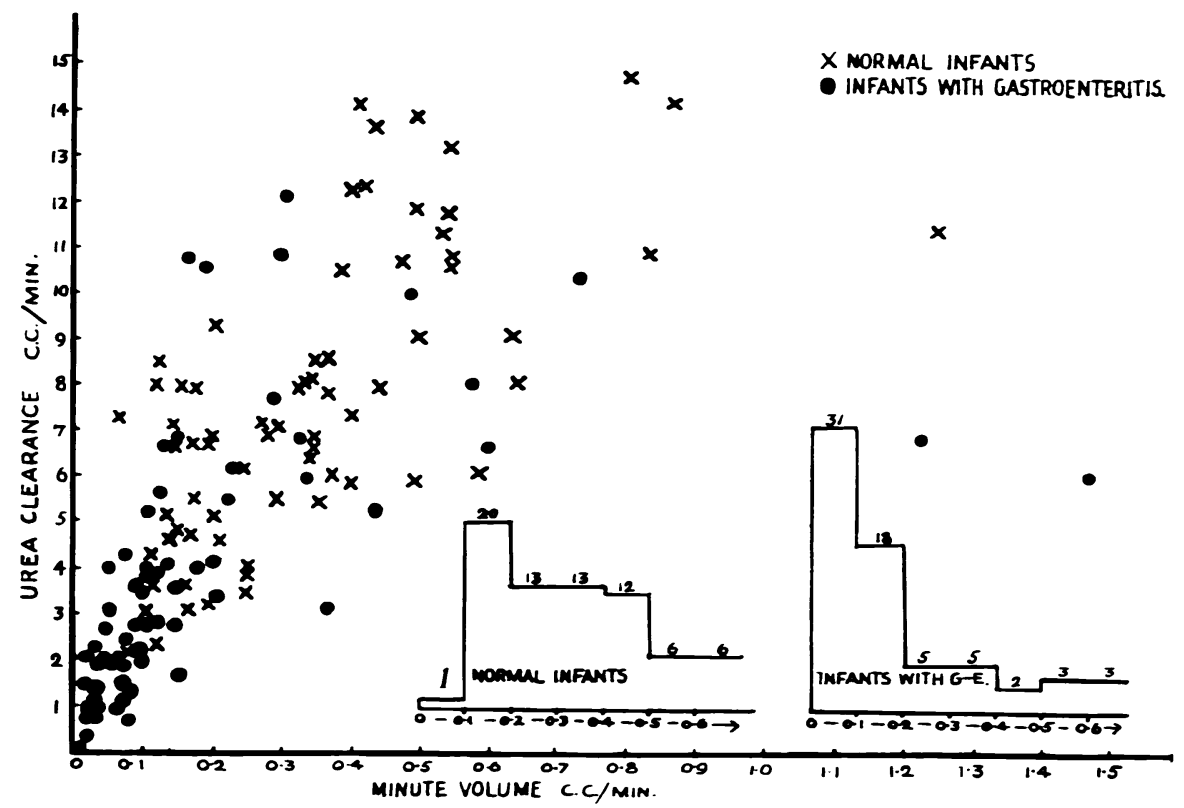

FIG. 1.-Urea clearances of infants aged 3-8 months.

and vomiting had a minute volume of less than $0 \cdot 1$ c.c./minute, whereas the minute volume of only one specimen from the normal infants was in this range.

When the infants with gastroenteritis were being studied, the periods during which the output of urine was measured included some when the dehydration of the patients had been relieved, even if only for an hour or two. Consequently the minute volumes of these samples were within the normal range. Since very low urine outputs were occasionally observed in some normal infants for short periods, the minute volumes of the two groups overlapped to some extent, and the comparison of their kidney functions was thus facilitated.

UREA CLEARANCES. Fig. 1 shows the urea clearances, $\frac{U \mathrm{~V}}{\mathrm{P}}$, of all the older babies plotted against their minute volumes. The former ranged from 0.045 to 14.8 c.c./minute and the latter from 0.0072 to 1.47 c.c./minute. It will be noted that:

1. The clearances varied with the minute volumes.

2. The urea clearances of the infants with gastroenteritis were frequently very low when the minute volumes were low, but when the minute volumes 
were in the normal range the clearances were comparable with those of normal babies. Moreover, on the few occasions when the minute volumes of the normal infants were low their urea clearances were correspondingly reduced.

It is probable, therefore, that the main reason for high blood ureas in dehydrated infants is their low output of urea, and that this in turn is due to their diminished flow of urine. This is supported by the fact that the blood urea may fall rapidly when the oliguria has been relieved. The blood urea of one of our patients fell from $186 \mathrm{mgm}$. $/ 100$ c.c. to $55 \mathrm{mgm}$./100 c.c. in less than twenty-four hours.

Anything which reduces the volume of the urine tends also to produce low urea clearances. In the course of treatment some infants have become oedematous following the administration of too much salt. Some of the lowest minute volumes and urea clearances shown in fig. 1 were noted in infants who had been treated in this way. Low minute volumes and low urea clearances have also been described in premature infants who were oedematous (Young, Hallum and McCance, 1941).

Fig. 1 shows that at any one minute volume the urea clearances of the whole group varied over an extensive range. A variation from one child to another was to be expected, but the urea clearances of healthy individual infants were sometimes found to vary surprisingly from time to time. Some evidence was also obtained that as death approached, or if a child were in extremis, the urea clearances might fall below their ' normal' levels. Table 1 illustrates both these points.

TABLE 1

THE VARIATIONS IN THE UREA CLEARANCES OF INDIVIDUAL INFANTS

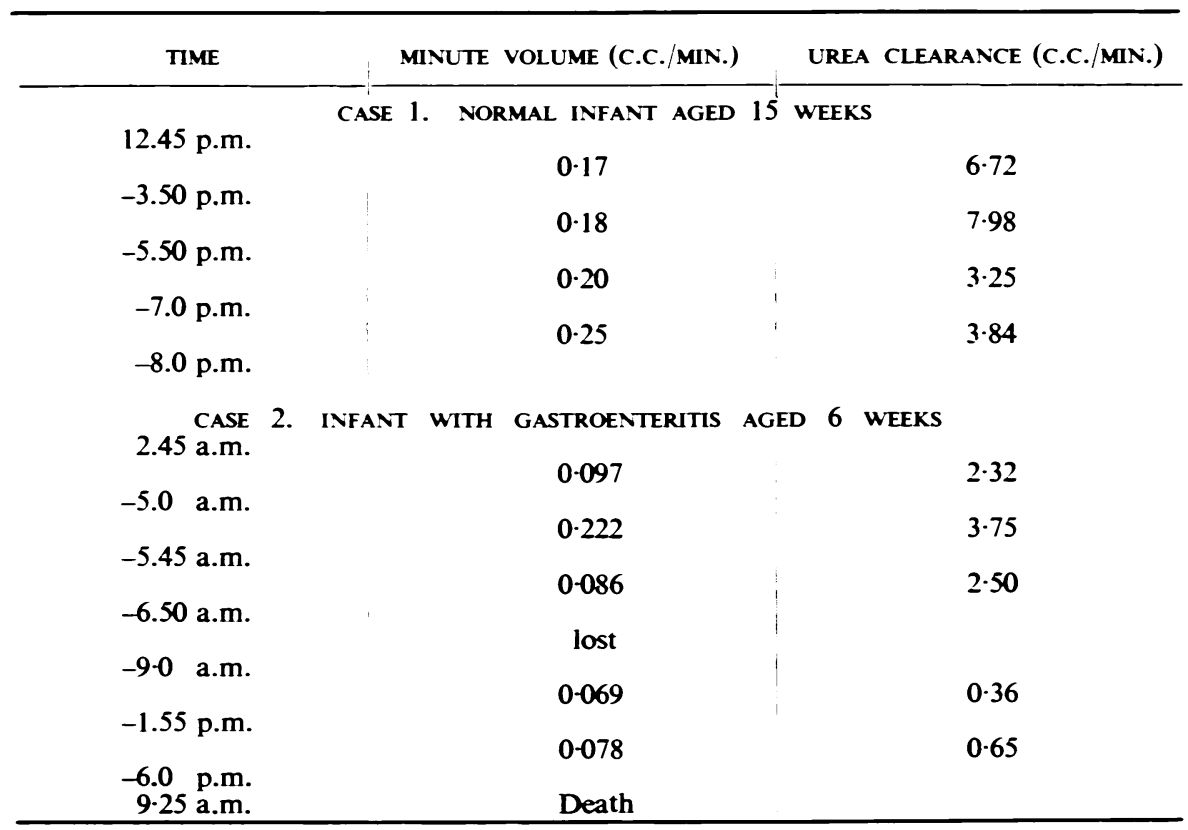


Case 1 was a thriving child aged fifteen weeks; and on July 16 his minute volumes hardly changed from 12.45 to 8.0 p.m. Nevertheless, his clearances before 5.50 p.m. were approximately double those from 5.50 to 8.0 p.m. Case 2 was a marasmic infant, aged six weeks, suffering from gastroenteritis. There was a big fall in his urea clearances fifteen to twenty-four hours before death, although the minute volumes of his urine were comparable with those obtained earlier on the same day.

Fig. 2 shows all the urea clearances of the two age groups, averaged and corrected for surface area as described by Young, Hallum and McCance (1941), and compared with those of premature and full-term new-born infants and with those of adults. It will be noted that the clearances increased with the age of the subjects. It is evident from the averaged clearances of the older

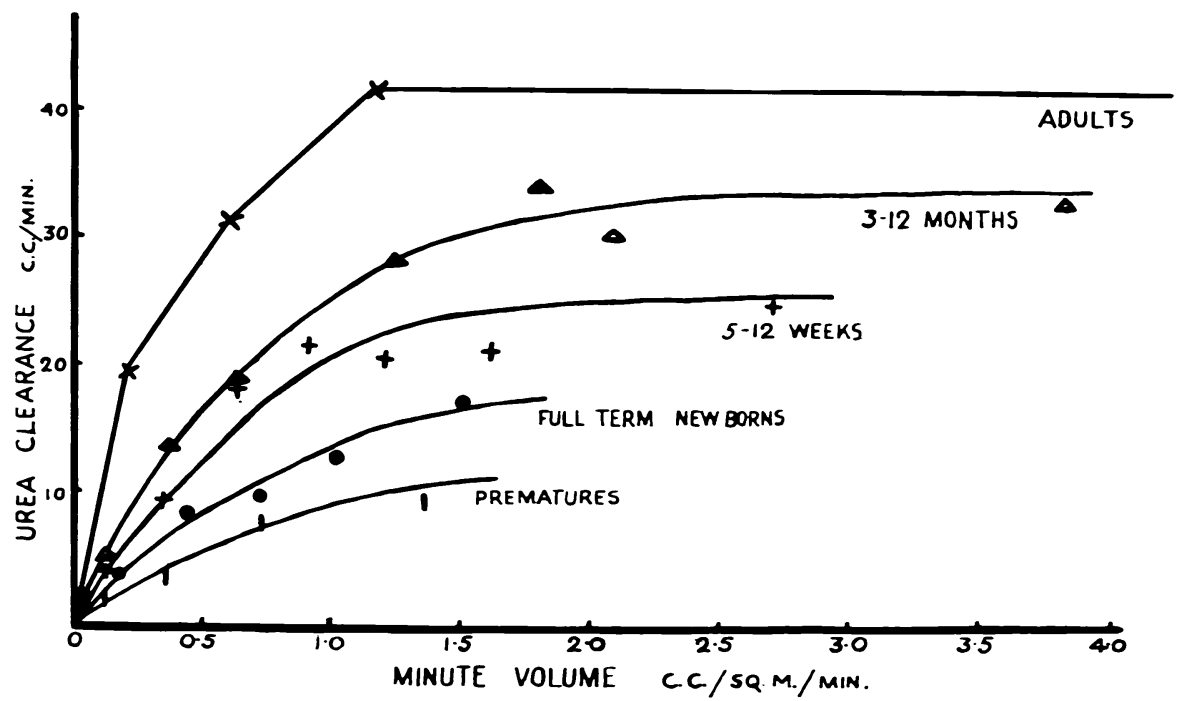

FIG. 2.-Comparison of the average urea clearances of adults and of infants at four different ages.

babies that some of the individual figures must have been very near the adult levels at high minute volumes. In each group of infants, however, the clearances varied more extensively with the minute volumes than they do in adults, so that, even among the older babies, clearances seldom approximated to the

TABLE 2

THE EFFECT OF URINE FLOW UPON THE $\frac{\text { INFANTILE }}{\text { ADULT }}$ UREA CLEARANCE

\begin{tabular}{|c|c|c|c|c|}
\hline \multirow{4}{*}{$\begin{array}{c}\text { VOLUME OF } \\
\text { URINE } \\
\text { C.C./SQ.M./MIN. }\end{array}$} & \multicolumn{4}{|c|}{ AVERAGE INFANT UREA CLEARANCE C.C./SQ.M./MIN. } \\
\hline & \multicolumn{4}{|c|}{ ADULT UREA CLEARANCE C.C./SQ.M./MIN. } \\
\hline & PREMATURE & FULL-TERM & 5-12 WEEKS & 3-8 MONTHS \\
\hline & $\overline{\text { ADULT }}$ & $\overline{\text { ADULT }}$ & $\overline{\text { ADULT }}$ & ADULT \\
\hline $\begin{array}{l}0.3 \\
0.75 \\
1 \cdot 2 \\
\end{array}$ & $\begin{array}{l}0 \cdot 18 \\
0 \cdot 23 \\
0 \cdot 25\end{array}$ & $\begin{array}{l}0 \cdot 24 \\
0 \cdot 34 \\
0 \cdot 38\end{array}$ & $\begin{array}{l}0 \cdot 38 \\
0 \cdot 49 \\
0 \cdot 51\end{array}$ & $\begin{array}{l}0 \cdot 53 \\
0 \cdot 62 \\
0 \cdot 69\end{array}$ \\
\hline
\end{tabular}


adult levels at low minute volumes. This is demonstrated by the ratios of infant to adult clearances which are shown in table 2 . In no group of infants did the ratio reach $1 \cdot 0$, and it was always smaller at low minute volumes than it was at high ones.

THE RELATIONSHIP BetWeEN THE UREA CLEARANCES AND THE GLOMERULAR FILTRATION RATES

The glomerular filtration rates (measured by the inulin clearances) of a few infants with gastroenteritis were estimated at the same time as the urea clearances. The results are shown in table 3 . It will be noted that :

TABLE 3

INULIN AND UREA CLEARANCES

\begin{tabular}{|c|c|c|c|c|}
\hline NAME & $\begin{array}{l}\text { URINE VOLUME } \\
\text { C.C./SQ.M./MIN. }\end{array}$ & $\begin{array}{l}\text { INULN CLEARANCE } \\
\text { C.C./SQ.M./MIN. }\end{array}$ & $\begin{array}{l}\text { UREA CLEARANCE } \\
\text { C.C./SQ.M./MIN. }\end{array}$ & $\frac{\mathrm{U}}{\mathrm{I}}$ CLEARANCE RATIO \\
\hline $\mathrm{T}$ & $\begin{array}{l}0.430 \\
0.485 \\
1 \cdot 150\end{array}$ & $\begin{array}{l}12 \cdot 5 \\
11 \cdot 6 \\
18.6\end{array}$ & $\begin{array}{r}6.5 \\
6.9 \\
11.6\end{array}$ & $\begin{array}{l}0.52 \\
0.59 \\
0.62\end{array}$ \\
\hline$R$. & $\begin{array}{l}0.087 \\
0 \cdot 174\end{array}$ & $\begin{array}{r}9 \cdot 5 \\
16 \cdot 1\end{array}$ & $\begin{array}{l}3.0 \\
6 \cdot 1\end{array}$ & $\begin{array}{l}0 \cdot 31 \\
0 \cdot 38\end{array}$ \\
\hline B. & $\begin{array}{l}0.361 \\
0.364 \\
0.266\end{array}$ & $\begin{array}{l}39 \cdot 8 \\
43 \cdot 0 \\
44 \cdot 4\end{array}$ & $\begin{array}{l}11 \cdot 3 \\
13.3 \\
15.6\end{array}$ & $\begin{array}{l}0.28 \\
0.31 \\
0.35\end{array}$ \\
\hline C. & $\begin{array}{l}0 \cdot 502 \\
2 \cdot 080 \\
4 \cdot 350 \\
5 \cdot 180\end{array}$ & $\begin{array}{l}30 \cdot 2 \\
50 \cdot 1 \\
51 \cdot 2 \\
45 \cdot 0\end{array}$ & $\begin{array}{r}9 \cdot 5 \\
23 \cdot 4 \\
24 \cdot 2 \\
21 \cdot 2\end{array}$ & $\begin{array}{l}0.31 \\
0.46 \\
0.47 \\
0.47\end{array}$ \\
\hline A. & $\begin{array}{l}0 \cdot 192 \\
0.221 \\
0 \cdot 302\end{array}$ & $\begin{array}{l}14 \cdot 7 \\
17 \cdot 3 \\
19 \cdot 5\end{array}$ & $\begin{array}{l}3 \cdot 1 \\
4 \cdot 7 \\
6 \cdot 4\end{array}$ & $\begin{array}{l}0 \cdot 19 \\
0 \cdot 22 \\
0 \cdot 30\end{array}$ \\
\hline Ta. & $\begin{array}{l}0.442 \\
1.060\end{array}$ & $\begin{array}{l}14 \cdot 8 \\
22 \cdot 8\end{array}$ & $\begin{array}{l}10 \cdot 4 \\
19 \cdot 1\end{array}$ & $\begin{array}{l}0 \cdot 70 \\
0.83\end{array}$ \\
\hline Sm. & $\begin{array}{l}0.630 \\
2-080\end{array}$ & $\begin{array}{l}26 \cdot 9 \\
61 \cdot 8\end{array}$ & $\begin{array}{l}15 \cdot 7 \\
29 \cdot 5\end{array}$ & $\begin{array}{l}0.56 \\
0.48\end{array}$ \\
\hline
\end{tabular}

1. The inulin clearances are all lower than the adult standard which may be taken to be 70 c.c./sq.m./min. These observations, which were made in 1939, are in agreement with the findings of Barnett (1940), who employed an indirect method to estimate the inulin clearances of some newborn infants and others aged two to seven-and-a-half weeks. He found that on the basis of surface area the inulin clearances at birth were less than 50 per cent. of those in adult life. As he did not collect the urine of his subjects the minute volumes at the times at which the clearances were measured are unknown.

2. A change of any magnitude in the minute volumes was always accompanied by a change of the clearances in the same direction, but it is clear from baby $\mathrm{C}$ that there is probably a limit above which a further increase in the minute volume leaves the clearances unchanged. 
3. The $\frac{U}{I}$ clearance ratios were of the same order as those previously found in adults and newborn babies.

4. The $\frac{U}{I}$ clearance ratios tended as in adults to increase with the minute volume, but this effect was small compared with the changes induced in both inulin and urea clearances by changes in the minute volumes. It would seem, therefore, that the urea clearances of infants may be used as a guide to the behaviour of the glomerular filtration rates, and, if a sufficient number of inulin clearances had been carried out, a progressive increase with age would almost certainly have been found (fig. 2). It has been stated that the glomerular filtration rate of adults and of dogs remains relatively constant over the normal range of minute volumes (Smith, 1937), and only falls when the minute volumes are very small (Chesley, 1938; Steinitz and Türkand, 1940), or in functional renal disorganization due to disease (McCance and Widdowson, 1939; Black, Powell and Smith, 1941). The evidence which is now presented suggests that during infancy the glomerular filtration rate is lower and not nearly so stable as it is in adult life. If this be true, then the excretion of minerals and of waste products of metabolism other than urea must also be affected by these characteristics of the glomerular filtration rate.

Two recent studies of the histology of the kidney in infancy add interest to the present findings. Gruenwald and Popper (1940) examined the renal glomerulus in early post-natal life, and observed that until birth the glomerular loops were matted together and invaginated in a sac of high columnar epithelium. After birth the epithelial sac burst and the loops expanded, but in early postnatal life the peaks of the loops were still covered with high columnar epithelium. Gruenwald and Popper considered that this layer might impede glomerular filtration. The low glomerular filtration rates which have been described suggest that it does. Kaufmann (1940) studied the juxta-glomerular corpuscles of Goormaghtigh in normal and diseased human kidneys removed surgically and at autopsy. These special groups of cells are situated chiefly at the vascular pole of the glomerulus and may be concerned with the regulation of the glomerular filtration rate. They were not observed in the kidneys of stillborn infants or children up to the age of two years. It is thought that their absence may explain the instability of the glomerular filtration rate in young children.

THE EXCRETION OF MINERALS. The excretion of electrolytes is governed by factors other than the glomerular filtration rates and the minute volumes. The ions in question all belong to the so-called threshold class of substances, and a small rise or fall in their plasma concentrations may make an enormous difference to their output in the urine. To some extent, moreover, the suprarenal cortex governs the reabsorption of sodium, chloride and potassium in all animals, and in dogs the posterior pituitary has also been shown to be concerned with the concentration of chlorides in the urine (Paine and Nelson, 1939). Leiter (1941) indeed took the view that 'extrarenal factors are too important in the case of the major electrolytes to justify the expectation of much progress from . . . clearance studies.' This seems to have been unwarrantable 
pessimism, for a study of clearances alone has been enough to show that there are certain interesting differences between infants and adults in the way in which electrolytes are excreted. Thus the sodium, chloride and potassium clearances of premature and full-term normal infants have already been shown to be of a very low order compared with those of adults on the basis of their respective surface areas. As might have been expected, the clearances of normal babies aged two to six months have now been found to lie between those of newborn babies and of adults. This finding, however, will not be further discussed since this study has been concerned primarily with infants suffering from the effects of dehydration.

THE CHLORIDE AND SODIUM CLEARANCES. The concentration of chlorides in the plasma of untreated patients with gastroenteritis is often above normal limits (Aldridge, 1941, a, b), and it may reach very high levels after the administration of saline. The reluctance, by adult standards, of the infant kidney to excrete chlorides can easily be demonstrated by the following consideration. The average concentration of chloride found in the urine of infants, whose plasma chlorides were above $400 \mathrm{mgm}$. $/ 100$ c.c., was $314 \mathrm{mgm} . / 100$ c.c. In adults a figure round 1 per cent. would have been expected if forced excretion of chlorides was in progress (Baird and Haldane, 1922; de Wesselow, 1925-26).

Fig. 3 shows the chloride clearances of all the infants aged three to eight

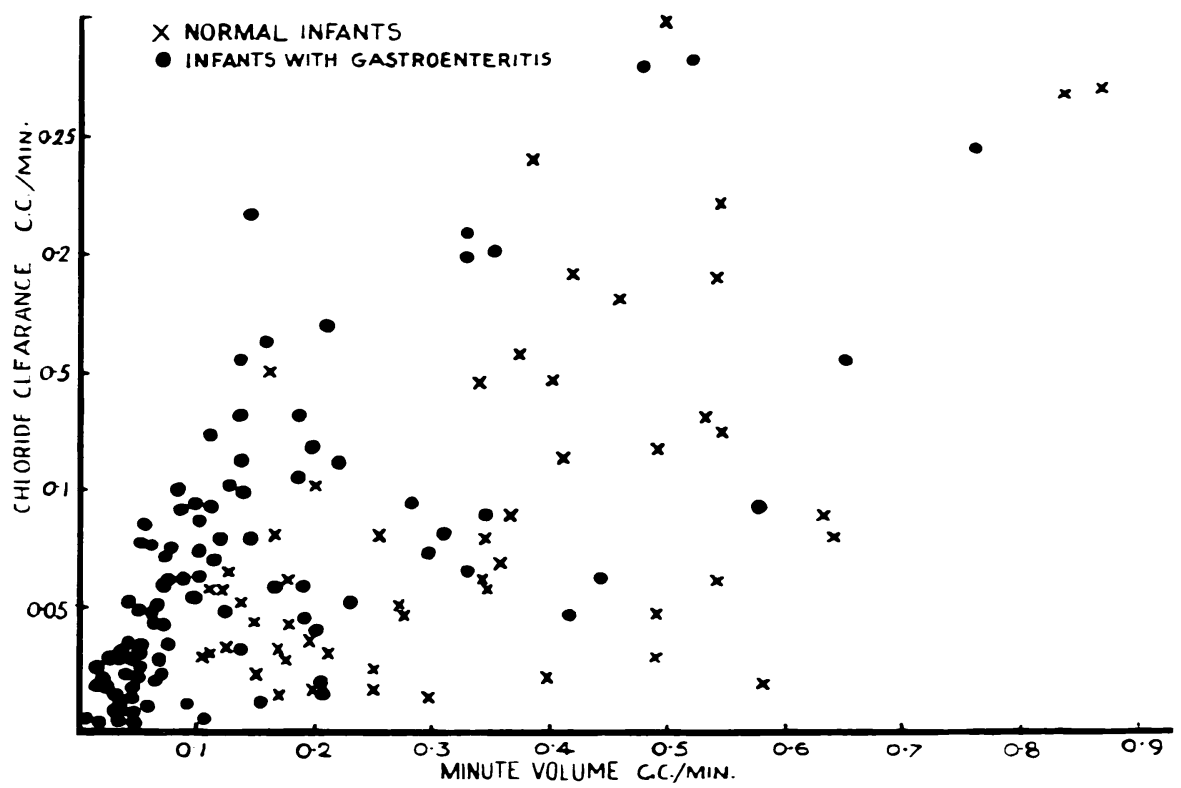

FIG. 3.-Chloride clearances of infants aged 3-8 months.

(For graphical convenience seven chloride clearances above $\mathbf{0 . 3}$ c.c./min. and three at minute volumes over 0.9 c.c. $/ \mathrm{min}$. have been omitted.)

months, whether they were normal or suffering from the immediate or subsequent effects of dehydration. The scatter is very great, and further analyses of these results will be made, but fig. 3 shows quite clearly that, although there is a tendency for the clearances to vary with the minute volumes, at com- 
parable minute volumes the clearances of the children suffering from diarrhoea and vomiting were fully as high, and often much higher, than those of normal children of the same age. This certainly does not suggest renal failure, but it must be recalled that the concentration of chloride in these sick babies' plasma was often above normal, and that this might in itself be expected to raise the clearances, and might out-weigh other factors which were depressing them. Accordingly, the plasma chlorides and the clearances have been averaged at comparable minute volumes and the results are given in table 4 . It will be seen that, as suggested by fig. 3 , at all comparable minute volumes the clearances of the sick children were higher than those of the normal. At most minute volumes, however, the plasma chlorides were also higher, so that the clearances are not directly comparable. At urine volumes between 0.2 and 0.3 c.c./minute, however, the plasma chlorides were the same, and the clearances of the sick children higher. This evidence, therefore, indicates that their kidneys were functioning quite normally, by infant standards, and in this it corroborates the conclusions reached from a study of the urea clearances. Table 4 also shows that the clearances of the sick children varied with the minute volumes much more extensively than did the clearances of the normal children. The minute volume is obviously a factor limiting the clearances of babies who are, or who have been, dehydrated and whose plasma chlorides are raised. The minute volume, indeed, seems much more important under these conditions than the actual plasma level. This is clearly brought out by a study of table 5 , which shows the sodium and chloride clearances at various minute volumes of all the sick children whose plasma chlorides exceeded $400 \mathrm{mgm} . / 100$ c.c., i.e. were grossly raised. It will be noted that the smaller the minute volumes

TABLE 4

A COMPARISON OF THE AVERAGED CHLORIDE CLEARANCES OF INFANTS WITH AND WITHOUT GASTROENTERITIS

\begin{tabular}{|c|c|c|c|c|c|}
\hline & \multirow{2}{*}{$\begin{array}{l}\text { MINUTE } \\
\text { VOLUME } \\
\text { c.C./MIN. }\end{array}$} & \multicolumn{2}{|c|}{ NORMAL INFANTS } & \multicolumn{2}{|c|}{ INFANTS WITH GASTROENTERITIS } \\
\hline & & $\begin{array}{c}\text { PLASMA } \\
\text { CHLORIDE } \\
\text { MG. } / 100 \text { C.C. }\end{array}$ & $\begin{array}{l}\text { CHLORIDE } \\
\text { CLEARANCE } \\
\text { C.C./MIN. }\end{array}$ & $\begin{array}{c}\text { PLASMA } \\
\text { CHLORIDE } \\
\text { MG. } / 100 \text { C.C. }\end{array}$ & $\begin{array}{c}\text { CHLORIDE } \\
\text { CLEARANCE } \\
\text { C.C./MIN. }\end{array}$ \\
\hline $\begin{array}{l}\text { Infants aged } \\
3-8 \text { months : }\end{array}$ & $\begin{array}{r}0.0-0.1 \\
0.1-0.2 \\
0.2-0.3 \\
0.3-0.4 \\
0.4-1.0 \\
\text { Over } 1.0\end{array}$ & $\begin{array}{l}385 \\
351 \\
366 \\
366 \\
363 \\
381\end{array}$ & $\begin{array}{l}\overline{0-064} \\
0.042 \\
0.145 \\
0.130 \\
0.122\end{array}$ & $\begin{array}{l}417 \\
394 \\
366 \\
411 \\
388 \\
416\end{array}$ & $\begin{array}{l}0-037 \\
0-091 \\
0-074 \\
0.266 \\
0.316 \\
1 \cdot 220\end{array}$ \\
\hline $\begin{array}{l}\text { Infants aged } \\
5-12 \text { weeks : }\end{array}$ & $\begin{array}{l}0-0-0 \cdot 1 \\
0.1-0.2 \\
0.2-0.3 \\
0.3-0.4 \\
0.4\end{array}$ & $\begin{array}{l}348 \\
382 \\
378 \\
383 \\
372\end{array}$ & $\begin{array}{l}0-012 \\
0-021 \\
0-051 \\
0-071 \\
0-054\end{array}$ & $\begin{array}{c}424 \\
382 \\
398 \\
- \\
-\end{array}$ & $\begin{array}{c}0-024 \\
0-049 \\
0.129 \\
- \\
-\end{array}$ \\
\hline
\end{tabular}


the lower were the chloride clearances, although, at the same time, the higher were the plasma chlorides. The same relationships hold for the sodium clearances and the plasma sodiums of the older babies (also shown in table 5). The sodium figures for the younger babies are the means of only four and five individual assays. They have, therefore, less significance than the others, and while they show like them an increase of the clearances with the minute volumes they indicate that the rise in the plasma sodiums may have had something to do with this result.

TABLE 5

THE EFFECT OF URINE FLOW UPON THE AVERAGED CHLORIDE AND SODIUM CLEARANCES OF INFANTS WHOSE PLASMA CHLORIDES WERE OVER 400 MGM./100 C.C.

\begin{tabular}{|c|c|c|c|c|c|}
\hline & $\begin{array}{l}\text { MINUTE } \\
\text { VOLUME }\end{array}$ & $\begin{array}{c}\text { PLASMA } \\
\text { CHLORIDE } \\
\text { (MGM. } / 100 \text { C.C.) }\end{array}$ & $\begin{array}{l}\text { CHLORIDE } \\
\text { CLEARANCES } \\
\text { (C.C./MIN.) }\end{array}$ & $\begin{array}{c}\text { PLASMA } \\
\text { SODIUM } \\
\text { (MGM./100 c.C.) }\end{array}$ & $\begin{array}{c}\text { SODIUM } \\
\text { CLEARANCES } \\
\text { (C.C./MIN.) }\end{array}$ \\
\hline $\begin{array}{l}\text { Infants aged } \\
3-8 \text { months : }\end{array}$ & $\begin{array}{l}0.054 \\
0.142 \\
0.295 \\
0.771\end{array}$ & $\begin{array}{l}464 \\
452 \\
430 \\
420\end{array}$ & $\begin{array}{l}0.040 \\
0.099 \\
0.246 \\
0.730\end{array}$ & $\begin{array}{l}345 \\
339 \\
317 \\
298\end{array}$ & $\begin{array}{l}0.016 \\
0.036 \\
0.164 \\
0.232\end{array}$ \\
\hline $\begin{array}{l}\text { Infants aged } \\
5-12 \text { weeks : }\end{array}$ & $\begin{array}{l}0-032 \\
0-079 \\
0.3 *\end{array}$ & $\begin{array}{l}444 \\
412 \\
418\end{array}$ & $\begin{array}{l}0-011 \\
0-044 \\
0 \cdot 213\end{array}$ & $\begin{array}{r}338 \\
376 \\
-\end{array}$ & $\begin{array}{c}0-020 \\
0-023 \\
-\end{array}$ \\
\hline
\end{tabular}

* One sample only.

The fact that there has been a closer relationship between the minute volumes and the chloride clearances in the sick infants than there has been in the normal ones can be explained as follows, and is in keeping with some of the observations which have been made upon chloride excretion in adults. When the plasma chlorides are at or near the 'threshold' value, or when for some hormonal reason (Thorn, Engel and Lewis, 1941) the excretion of chlorides is more or less in abeyance, the urine formed at the same time, whatever its volume, can easily carry the quota of chlorides assigned to it without straining the energetics of the renal parenchyma. When, however, the plasma chlorides are high, or a high rate of excretion is demanded, then the amount of chloride to reach the bladder is determined by urinary and renal limitations such as the osmotic pressure of the urine, and its volume. An association between minute volume and chloride output, similar to the one now being presented in dehydrated or over-treated infants, was found by de Wesselow (1925-26) in adults who had taken $4 \mathrm{gm}$. of sodium or potassium chloride. Three hours later the chlorides in the urine had always risen to about 1 per cent. although the volumes varied from 50 to 132 c.c./hour at the same time. Baird and Haldane (1922) studied the adult response to much larger doses (38 gm.) of sodium chloride, taken by mouth as hypertonic or isotonic solutions. They showed that the concentration of chloride in the urine rapidly rose to a steady value of about 1.03 per cent. whatever the diuresis, and remained there for some seven or 
eight hours. Had the chloride clearances been determined either by de Wesselow or Baird and Haldane they would have been found to vary closely with the minute volumes.

The sodium in the plasma is frequently low (not high) in untreated cases of gastroenteritis, and this may be one of the factors limiting the excretion of chlorides in such children. During treatment with saline, however, the serum sodiums may rise to very high levels, and in four babies, figures above 380 mgm./100 c.c. were recorded. Even at these plasma levels, however, the clearances were very low at low minute volumes.

Potassium Clearances. Hall and Langley (1940) have studied the excretion of potassium by three normal adults. They found that, when the intakes in the food were approximately constant, the plasma potassium of their subjects remained at about $17 \mathrm{mgm} . / 100$ c.c. and the clearances were maintained at about 16 c.c./sq.m./min. at all minute volumes above 0.6 c.c. $/ \mathrm{sq} . \mathrm{m} . / \mathrm{min}$. When the minute volumes fell below this level, however, the clearances fell too, and a reduced glomerular filtration rate was put forward as the explanation. If this is correct, and if the evidence already presented be accepted that in infancy the glomerular filtration rates vary with the minute volumes over a much wider range than they do in adults, then one would expect to find that, in infancy, the potassium clearances varied with the urine flow, and particularly with the urea clearances, over the whole range of minute volumes. The potassium clearances of each child were, therefore, compared with his urea clearances arranged in ascending order. The clearances of a few cases which were selected more or less at random are shown in table 6, and they demonstrate that the expectation that the potassium clearances would vary with the urea clearances was correct. Few exceptions were found among the normal infants, and generally speaking the same was true of the infants who were suffering from dehydration, but among them it was noticed that the first specimen passed as the dehydration was being relieved gave an exceptionally high potassium clearance. There is no obvious explanation for this at present, but it seems wise to put it on record. It has already been shown that dehydration does not as a rule reduce the urea clearances except in so far as it reduces the minute volumes. This appears also to be true of potassium, for the

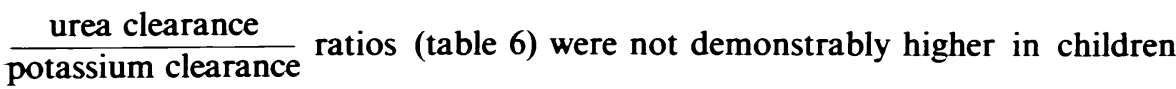
who were suffering from the effects of dehydration. It may, however, be noted in passing that the clearance ratios of the infants with gastroenteritis varied very much more than those of normal infants. The range was 1.9 to 23.0 for the normal infants, and 0.46 to 80.6 for the infants suffering from gastroenteritis.

THE OSMOTIC PRESSURE OF THE URINE. In the previous investigations on premature and full-term infants, an indication of the relative osmotic pressures of the urine and of the plasma was obtained from the ratio

$$
\frac{\mathrm{m} \text {. eq. of urea }-\mathrm{m} \text {. eq. of electrolytes in the urine }}{\mathrm{m} \text {. eq. of urea }-\mathrm{m} \text {. eq. of electrolytes in the plasma }}
$$


THE SECRETION OF URINE BY INFANTS

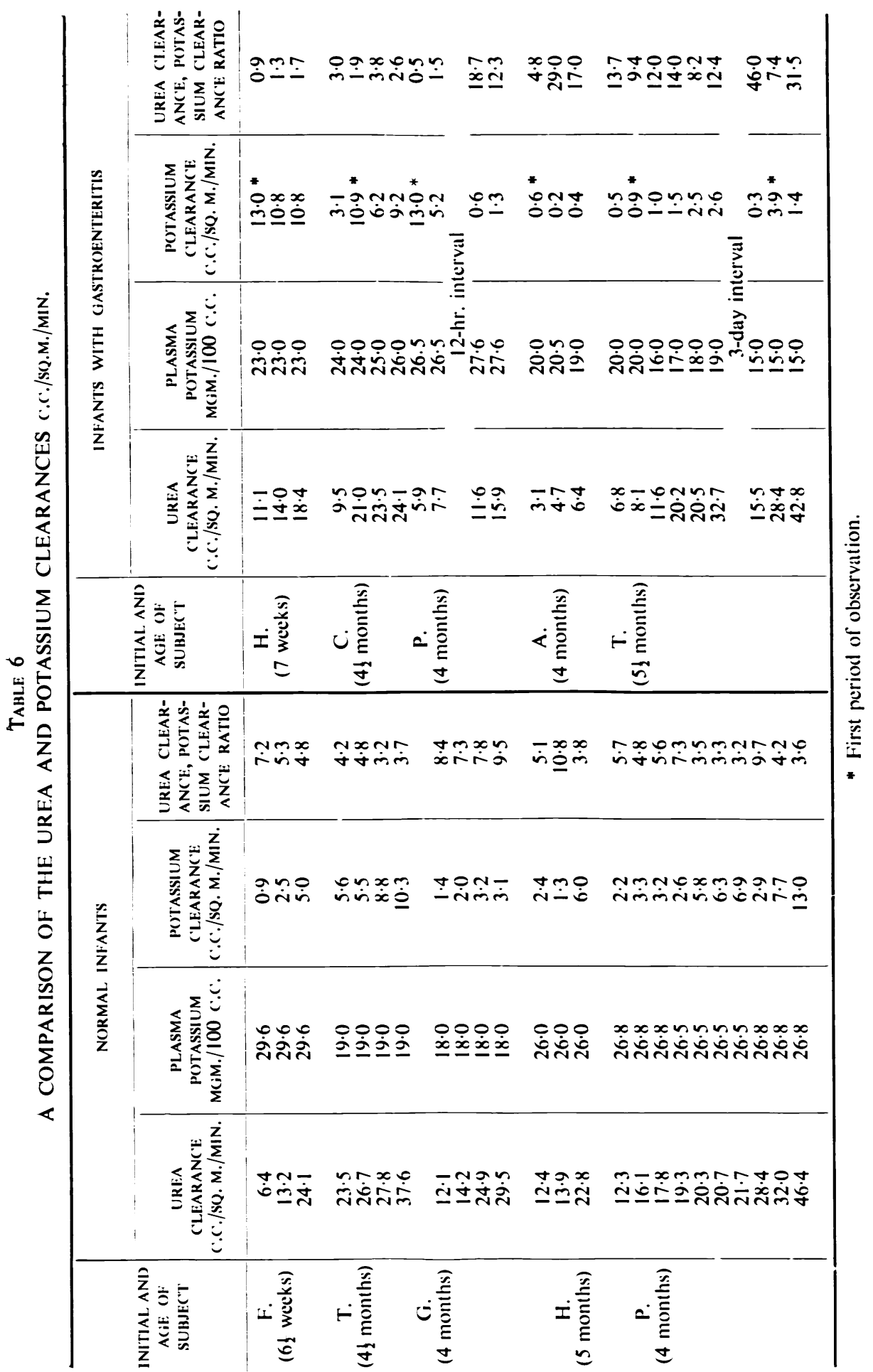


and it was found that this $U / P$ ratio was very small by adult standards at comparable low and average minute volumes. Such small ratios are really another expression of the fact that, while the plasma concentrations of urea and electrolytes in healthy infants are similar to those of adults, their urines are much more dilute at low urine volumes, and consequently their clearances are considerably lower.

The $\mathrm{U} / \mathrm{P}$ ratios of the groups of babies which have now been studied have also tended to be low. Fig. 4 shows the ratios of all the younger infants plotted

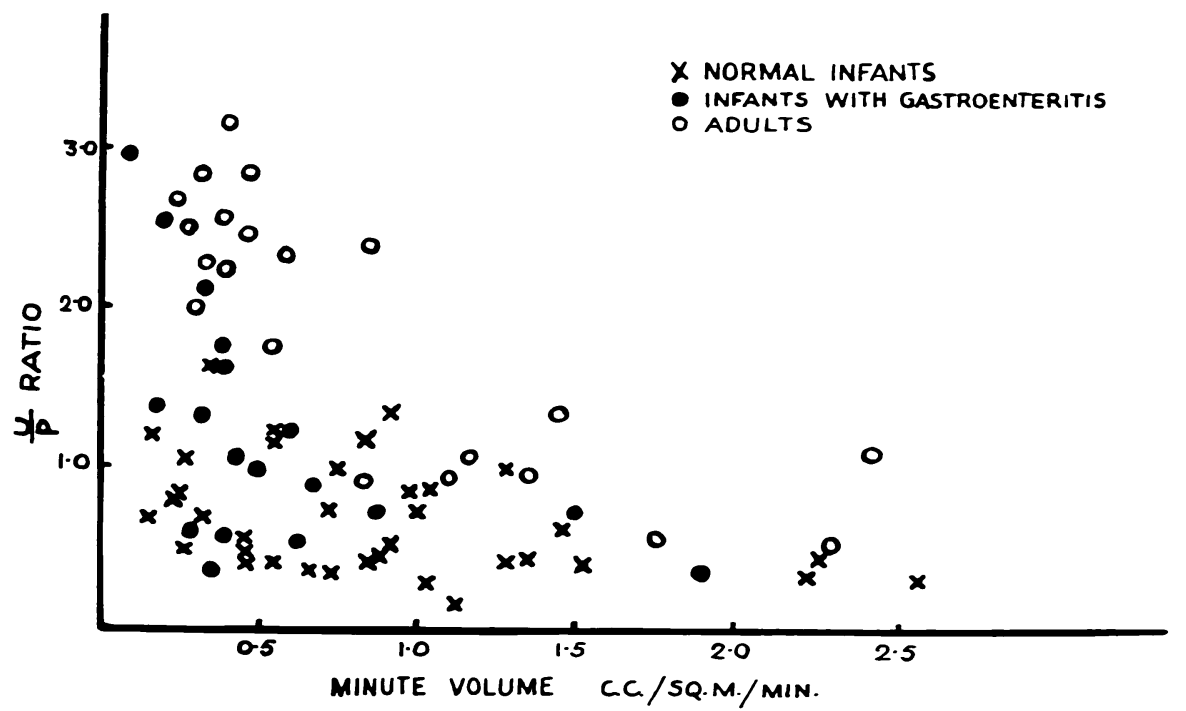

FIG. 4.-Comparison of the $\frac{\text { Urine }}{\text { Plasma }}$ crystalloid concentrations of infants aged 5-12 weeks and of adults.

against the minute volumes/sq.m./min., and the ratios of a few normal adults have been added for comparison. It will be noted that when the minute volume was below 0.5 all the adult ratios were above 2 , whereas none of the normal infant's ratios reached this level. It will also be noted that there was no obvious tendency for the ratios of the sick children to be any lower than those of the normal children. In fact, the three highest baby ratios, all of which exceeded 2, were given by abnormal children, and further analysis of the data shows that they were all given by a single child whose blood urea was $136 \mathrm{mgm} . / 100 \mathrm{c.c}$. The concentrations of urea in the three samples of this infant's urine were $3.02,4.18$ and 3.76 per cent. The effect of a high blood urea on the $U / P$ ratio was discussed in connection with the premature infants. It was pointed out that the proportion of the osmotic pressure of the urine due to urea is usually a large one, but the greater part of the osmotic pressure of the plasma is due to electrolytes. Urea is not an important part even when the plasma ureas are high. Since the urea clearances in infancy usually seem to be unaffected by the height of the blood urea, even if this has been raised by dehydration and oliguria, the $U / P$ ratios tend to increase rapidly as the blood urea 
rises. This preponderating importance of urea in regulating the $U / P$ ratios was clearly demonstrated in the investigation of premature infants, for in them the electrolyte clearances were usually so low that the concentration of minerals in the urine could almost (save in one exceptional infant) have been neglected. A high blood urea seems even at two or three months of age still to be the most frequent and most potent cause of a high $U / P$ ratio. but factors which tend to raise the mineral output in the urine have to be considered more often at these ages. These have already been discussed in connexion with the excretion of electrolytes and seem to be: (1) an increased output of sodium chloride after saline administration. This was the cause of one exceptionally high ratio previously reported in newborn infants; (2) the high potassium clearances which have been found to follow the relief of dehydration.

These results corroborate the findings of Maizels and McArthur (1928-29; 1929-30) and show how their limited data led them to what now appears to have been an erroneous conclusion. These authors interpreted their results as indicating specific failure of the kidney to excrete minerals. They were probably dealing with the normal response of infants to dehydration. They might have modified their suggestions had they had the opportunity to investigate normal infants.

\section{Discussion}

The results of this investigation invite discussion under two headings. The first is the kidney function of the normal control series and its relationship to the same function in adults and in younger children. In general terms this is not difficult, although there are still many details which are obscure. It may be stated broadly that infants of the ages here investigated have kidneys which are functionally intermediate between the adult and newborn types. Their urea clearances show their transitional position very well (fig. 2) and their inulin and mineral clearances fall into the same place. It is evident, therefore, that the adult type of function is not acquired in the first few weeks or even months of life, and probably not till at least the end of the first year. Traces of the infantile type of function may even persist in some children till well into the second year, and indeed the excretion of minerals has been so little investigated at all ages, that interesting developmental changes may be met with until much later in life.

The ways in which infants' kidneys differ functionally from adults may now provisionally be summarized, all comparisons being made on the basis of surface area. They have much lower glomerular filtration rates and urea clearances, and both vary much more extensively with the urine volumes than they do in adults - at any rate at normal flows. There is a lack of information, however, about the adult glomerular filtration rate at some urine flows which makes it difficult to be more explicit on this matter. Infants have much lower mineral clearances than adults, and even when there is positive evidence from plasma levels, or the quantities of saline administered, that the organism must be overloaded with salt, the concentration of chlorides in the urine is often very low. When the output of urine falls, the infant does not increase the 
concentration of solutes in his urine in the way an adult does, and consequently, with minor exceptions which have been discussed, an infant's urine is always (even at low minute volumes) a dilute urine. Kerpel-Fronius (1931) studied the response of a dog, ten days old, to a 'dehydration' diet, and compared it with that of a dog aged four months. He showed that the maximum concentration of nitrogen in the urine of the young dog was much lower than in that of the older dog. The observation suggests that man is not the only mammal in which the adult type of kidney function has not been established at birth.

The results here set out help to explain many well-known features of child health and disease. They show, particularly, why infants tolerate dehydration so badly, and misguided treatment almost worse. It is clear now why two or three large vomits and several watery stools may send a baby's blood urea up to $100 \mathrm{mgm} . / 100$ c.c. in a single day, and why the enthusiastic administration of a pint of normal saline may lead to unmistakable oedema. It is even conceivable that renal failure and nitrogen retention may precipitate diarrhoea and vomiting as a complication in babies who are suffering from some other disease. Schoenthal's (1929) work on one baby suggests that this may be so, and uraemic vomiting and diarrhoea are common enough in adults.

The second point for discussion is the effect of dehydration-caused by diarrhoea and perhaps vomiting as well-on the kidney. As outlined in the introduction, many have thought that diarrhoea and vomiting with their attendant dehydration brought about positive renal deterioration. This may to some extent be true, but the results which have now been obtained indicate that these suggestions were made by persons with insufficient knowledge of the function of the normal infant's kidney. The evidence here presented all goes to show that, whereas dehydration rapidly alters the serum chemistry in ways which suggest functional disorganization of the kidney, this organ is usually functioning in a perfectly normal infantile manner. As Schloss suggested as long ago as 1918, the pathological changes in the serum chemistry are due largely, and often solely, to the small quantity of water available for excretion.

\section{Summary}

1. Infants aged one to eight months have been found to have kidneys which are intermediate in functional capacity between those of adults and those of newborn children.

2. They have lower glomerular filtration rates and urea clearances than adults, expressed on the basis of surface area, and both vary with the minute volumes at normal rates of urine flow. The mineral clearances also tend to be lower than in later life. The solids in the urine do not rise as in adults when the minute volumes fall. Consequently, infants fail to maintain a constant internal milieu the moment they begin to pass small volumes of urine.

3. No evidence has been obtained that children who have been made short of water by diarrhoea or vomiting have a specific renal lesion. Their kidneys are functioning in the normal infantile manner and the abnormalities in their serum chemistry are due to the small amount of water available for excretion. 
The authors are grateful to Professor L. G. Parsons for the facilities which he placed at their disposal, and to the honorary staff of the Children's Hospital, Birmingham, for permission to investigate their cases. They also wish to thank Miss E. M. Hickmans, Ph.D., and her assistants in the Biochemical Department, and the Nursing Staff, for their help.

The expenses of the work were partially defrayed from a grant made by the Medical Research Council for work at this hospital, and W. F. Y. is indebted to the Council for a personal grant.

\section{REFERENCES}

Aldridge, A. G. V. (1941 a). Arch. Dis. Childh., 16, 81. (1941 b). Loc. cit., 182.

Allott, E. N. (1939). Lancet, 1, 1034.

Baird, M. M., and Haldane, J. B. S. (1922). J. Physiol., 56, 259.

Barnett, H. L. (1940). Proc. Soc. exp. Biol. N.Y., 44, 654.

Bessau, G., Rosenbaum, S., and Leichtentritt, B. (1922). Mschr. Kinderheilk., 23, 465.

Black, D. A. K., and Leese, A. (1940). Quart. J. Med., 9, 129.

_- Powell, J. F., and Ford Smith, A. (1941). J. Physiol., 99, 344.

Borst, J. G. G. (1938). Acta med. scand., 97, 68.

Brock, J., Thomas, E., and Peiper, A. (1934). Biologische Daten für den Kinderarzt., Berlin, 2.

Chesley, L. C. (1938). J. clin. Invest., 17, 591.

Cohen, H., Miller, P. R., and Kramer, B. (1933). J. Pediat., 3, 299.

Cooper, E. D. (1937). Arch. Dis. Childh., 12, 359.

Darrow, D. C., and Buckman, T. E. (1928). Amer. J. Dis. Child., 36, 248.

Gruenwald, P., and Popper, H. (1940). J. Urol., 43, 452.

Hall, V. E., and Langley, L. L. (1940). Proc. Soc. exp. Biol. N.Y., 44, 425.

Hamilton, B., Kajdi, L., and Meeker, D. (1929). Amer. J. Dis. Child., 38, 314.

Hartmann, A. F. (1928). Ibid., 35, 557.

- and Smyth, F. S. (1926). Ibid., 32, 1.

Hoag, L. A., and Marples, E. (1931). Ibid., 42, 291.

Kaufmann, W. (1940). Proc. Soc. exp. Biol. N.Y., 44, 227.

Kerpel-Fronius, E. (1931). Mschr. Kinderheilk., 51, 400.

Leiter, L. (1941). Ann. Rev. Physiol., 3, 519.

Maizels, M., and McArthur, C. N. (1928-29). Quart. J. Med., 22, 581. (1929-30). Ibid., 23, 171.

McCance, R. A., and Widdowson, E. M. (1937a). Lancet, 2, 247.

- - (1937 b). J. Physiol., 91, 222. (1939). Ibid., 95, 36.

and Young, W. F. (1941). Ibid., 99, 265.

Möller, E., McIntosh, J. F., and van Slyke, D. D. (1929). J. clin. Invest., 6, 427.

Paine, W. G., and Nelson, E. E. (1939). Proc. Soc. exp. Biol. N.Y., 42, 729.

Robinow, M., Hamilton, W. F., Woodbury, R. A., and Volpitto, P. P. (1939). Amer. J. Dis. Child., 58, 102.

Schoenthal, L. (1929). Ibid., 37, 244.

, Lurie, D., and Kelly, M. (1933). Ibid., 45, 41.

Schloss, O. M. (1918). Ibid., 15, 165.

Smith, H. W. (1937). The physiology of the kidney, New York.

Steinitz, K., and Türkand, H. (1940). J. clin. Invest., 19, 285.

Thorn, G. W., Engel, L. L., and Lewis, R. A. (1941). Science, 94, 348.

de Wesselow, O. L. V. (1925-26). Quart. J. Med., 19, 53.

Young, W. F., Hallum, J. L., and McCance, R. A. (1941). Arch. Dis. Childh., 16, 243. 